\title{
POSTGRADUATE RESEARCH IN PHARMACEUTICAL SCIENCES IN INDIA: A SURVEY OF SELECT PHARMACY PROFESSIONALS
}

\author{
GOURI PALSOKAR ${ }^{1}$, MADHUKAR TAJNE ${ }^{1}$ \\ 1Department of Pharmaceutical Sciences, RTM Nagpur University, Nagpur, Maharashtra, India \\ Email: gouripalsokar@gmail.com
}

Received: 28 Jan 2017, Revised and Accepted: 20 Apr 2017

\begin{abstract}
Objective: Research is a systematic investigation that involves the study of materials and sources in order to establish facts and reach new conclusions. Post-graduate pharmaceutical education develops the necessary skills among students which help them build their professional carriers and contribute towards the betterment of the healthcare industry and society in general. Hence, it is essential and mandatory to carry out some appropriate research work as a requirement of post-graduate courses in Pharmaceutical Sciences in India and abroad. In an era, where technology is changing rapidly, the research carried out by students must always be relevant to the present day, so that it can act as a bridge between innovation and utility with regard to patient care and compliance. The present work aims to investigate, as to how, the research at postgraduate level in pharmacy, could be carried out in a way so that it benefits the students and make their research relevant to the current industry needs.
\end{abstract}

Methods: The opinions of academicians from select academic institutions, professionals from pharmaceutical industries and postgraduates and Ph. D. students across India, were collected through questionnaires and by taking personal interviews. Data thus obtained was subjected to standard mathematical interpretations.

Results: About 48\% (65) of faculty members and 46\% (156) of Postgraduate and Ph. D. students from various parts of the country opined that projects in postgraduate courses should be executed partly in academic institutions and partly in industries. However, about 61\% (180) respondents from the pharmaceutical industry were of the view that the postgraduate students should undertake industrial projects. At the same time, some professionals were of the view that, students carrying out research work fully in the industry are many times left on their own as their industrial supervisors are unable to spare time to guide them.

Conclusion: The execution of research work carried out by post-graduate students should be evenly distributed in academic institutions as well as pharmaceutical industries, under the supervision of faculty and with active inputs from the industry.

Keywords: Pharmaceutical Education, Postgraduate Research, Industry-Academia linkages

(C) 2017 The Authors. Published by Innovare Academic Sciences Pvt Ltd. This is an open access article under the CC BY license (http://creativecommons.org/licenses/by/4.0/] DOI: http://dx.doi.org/10.22159/ijcpr.2017v9i4.20983

\section{INTRODUCTION}

Research includes an organised collection of data, derivation of information and facts established on the basis of the data for the advancement of knowledge. The goal of the research process is to produce new knowledge or a deep understanding of a topic or an issue. Research develops knowledge, skills and encourages the thinking process of students. Scientific research develops scientific outlook and technological education aims at developing skills of people to use technology to produce goods and services for needs of the society $[1,2]$.

Pharmacy is one of the oldest professions known to mankind. The technological developments in engineering and technology and research in Pharmaceutical Sciences have established it as one of the most sought after professions in recent times [3]. A student aspiring to become a part of the rapidly evolving Pharmaceutical Industry needs to keep himself updated with the recent trends in the industry and needs to have a sound research oriented approach to problemsolving. Research has been an integral component at the post graduate level in pharmaceutical education in India. The current scheme of post graduate education in pharmaceutical sciences in India requires a student to undergo theory courses in the first two semesters, followed by a research project in the last two semesters. This scheme is followed in most of the Universities in the UK and the US as well. The students are required to execute this research project, normally under the supervision of a faculty. While carrying out these projects, the students are required to develop analytical skills, scientific reasoning, and innovative thinking which will make them readily employable after completion of their course [4-7]. These budding pharmacists should be equipped with a futuristic approach and be adequately trained to survive in this ever competitive market [5-8]. Students should be trained in various aspects like manufacturing of dosage forms, analytical development, clinical research, regulatory affairs, quality control and quality assurance which would help them to build their professional careers and be at par with their global competitors [9]. Such skilled and trained professionals would definitely contribute to the growth of healthcare industry and will benefit the society at large $[10,11]$.

India is a hub for pharmaceutical industries ranking $3^{\text {rd }}$ in terms of volume and $14^{\text {th }}$ in terms of value globally [12]. With this phenomenal growth of pharmaceutical industries and the rapid change in technology, there is a need of trained, skilled and competent professionals $[9,11,13]$. Since research is one of the most important components in the design and delivery of effective drugs, research involving systematic investigation is essential at the post graduate level in pharmaceutical sciences. The research at postgraduate level should not only be an academic one but should also be relevant to present day practices in the industry [14]. For the conduct of such research, sophisticated instruments and high-end technology is required. Such facilities are normally available in the industry and are scarcely available in academic institutions, the exceptions being certain Institutions of National Importance. Thus, in most of the cases, the research at the post graduate level in pharmaceutical sciences is theoretical and superficial [15]. This calls for an in-depth study of the current state of research projects being carried out at post graduate level and suggest a better approach by taking into account the views of all stakeholders.

The primary objective of this study is to collect the opinion of select pharmacy professionals and examine their views as to how the research at postgraduate level in pharmacy could be carried out so 
that it benefits the students and make their research relevant to the current needs of the industry.

\section{MATERIALS AND METHODS}

This study was based on a survey conducted involving students pursuing their post graduate education in pharmaceutical sciences, $\mathrm{Ph}$. D. scholars, Faculty of various pharmaceutical institutions and professionals from the pharmaceutical industry which include some professionals from outside India. Data from professionals in India was collected using a structured questionnaire, whereas data from professionals outside India was collected by sending them an electronic questionnaire via e-mail [16-18]. A questionnaire consisting of fourteen questions was designed and was divided into two sections namely A and B. Section A contained eight questions and captured the demographic information of the respondents and Section B contained six questions for collecting the respondent's opinions about the post-graduate research projects in pharmaceutical sciences. Section B of the questionnaire included a variety of multiple choice questions and questions based on Likert scale etc., designed to fulfil the objectives of this research.

A pilot study was executed by conducting a survey in three educational institutions offering post-graduate courses in pharmaceutical sciences, using a group of hundred participants (students and faculty). The pilot study was necessary to evaluate the clarity of questions and to estimate the time needed to complete the questionnaire by any individual. Based on the responses received during the pilot study, necessary changes were incorporated in the questionnaire. The questionnaire was also reviewed by ten select professionals from Pharmaceutical industry.

The questionnaires for the final survey were distributed personally to all the respondents. The opinions of academicians, post-graduate and $\mathrm{PhD}$ students from thirteen academic institutions including three University departments, seven aided and unaided institutions, two National Institute of Pharmaceutical Education and Research and one IIT were collected. The subject composition with the percentage responses received is as shown in table 1. Multiple responses given by the respondents were considered.

The pharmaceutical industry is the prime stakeholder of the pharmacy profession and also the major area of employment for students completing post-graduate courses in pharmaceutical education in India. Opinions of professionals from thirty-seven pharmaceutical industries were collected by distributing the questionnaire personally. Personal interviews of select senior professionals above the level of vice-president in multinational pharmaceutical companies and senior academicians at the level of head of the University departments were taken and their views regarding the current structure of the post-graduate research projects were recorded.

\section{Data analysis}

All data collected was entered into and analysed using MS-Excel for Windows. The data were subjected to descriptive analysis and presented as frequencies and percentages.

\section{RESULTS}

Of the 770 respondents, $45 \%$ indicated that the students should carry out their projects in the industry. $10 \%$ of respondents opined that the research projects should be executed in the colleges or in academic institutions, $21 \%$ stated that the students should carry out industrial projects executed in academic institutions and $42 \%$ of the respondents were of the view that the projects should be executed partly in academic institution and partly in the industry. The percentage of overall views of all the respondents is summarised in fig. 1.

Table 1: Category-wise distribution of the respondent population along with their response percentage

\begin{tabular}{|c|c|c|c|}
\hline Category of respondents & Number of respondents targeted & Number of respondents who responded & Percentage response \\
\hline Post Graduate and Ph. D Students & 348 & ${ }^{\prime}$ & $97.41 \%$ \\
\hline Faculty & 164 & 136 & $82.92 \%$ \\
\hline Industry Professionals & 301 & 291 & $96.67 \%$ \\
\hline Professionals from outside India & 13 & 4 & $30.76 \%$ \\
\hline Total & 813 & 770 & $94.71 \%$ \\
\hline
\end{tabular}

However $37 \%$ of postgraduates and PhD students, $28 \%$ of faculty from academic institutions and $61 \%$ of professionals from pharmaceutical industry indicated that Industrial projects should be conducted at post graduate level in pharmaceutical sciences. $8 \%$ of students (M. Pharm and PhD), $20 \%$ of faculty and $7 \%$ of people from industry were of the view that projects at post graduate level in pharmacy should be executed in academic institution. $22 \%$ of students (M. Pharm and PhD), $30 \%$ of faculty and $15 \%$ of people from industry opined that industrial projects should be executed in academic institutions. The percentage of students, faculty and industry indicating responses are summarised in fig. 2.

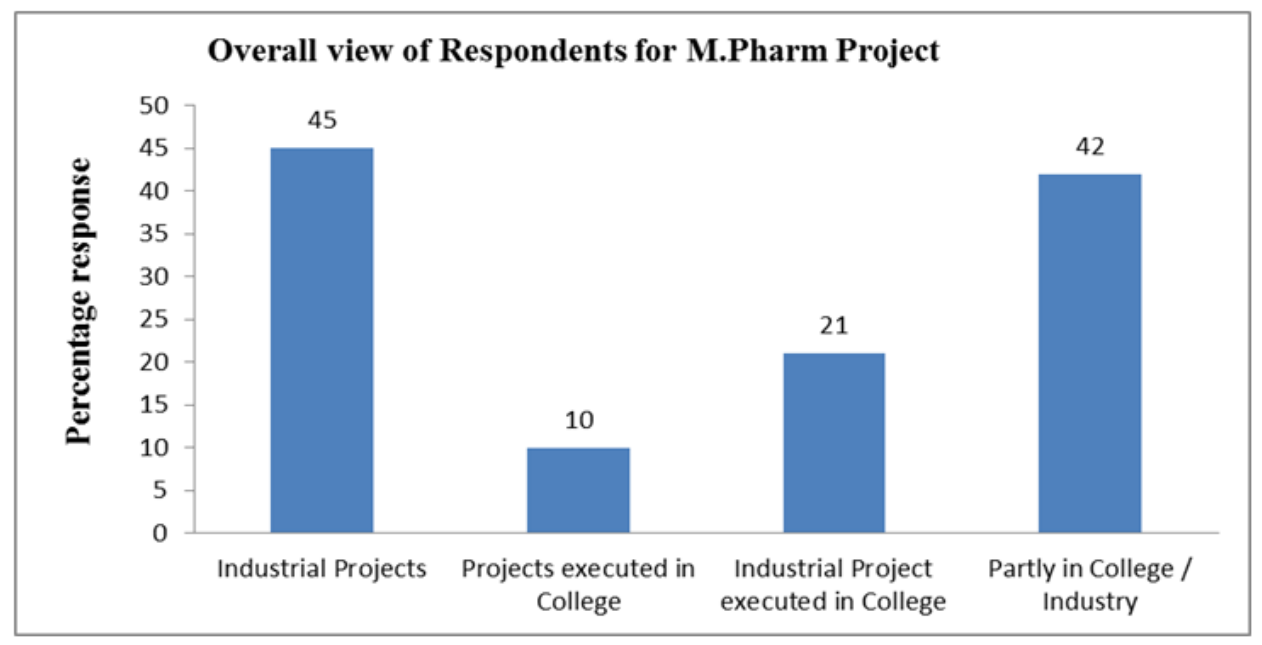

Fig. 1: Percentage of overall views of respondents 
Moreover $46 \%$ of students, $48 \%$ of faculty and $34 \%$ people from pharmaceutical industry indicated research projects at M. Pharm level should be executed partly in academic institutions and partly in the industry.

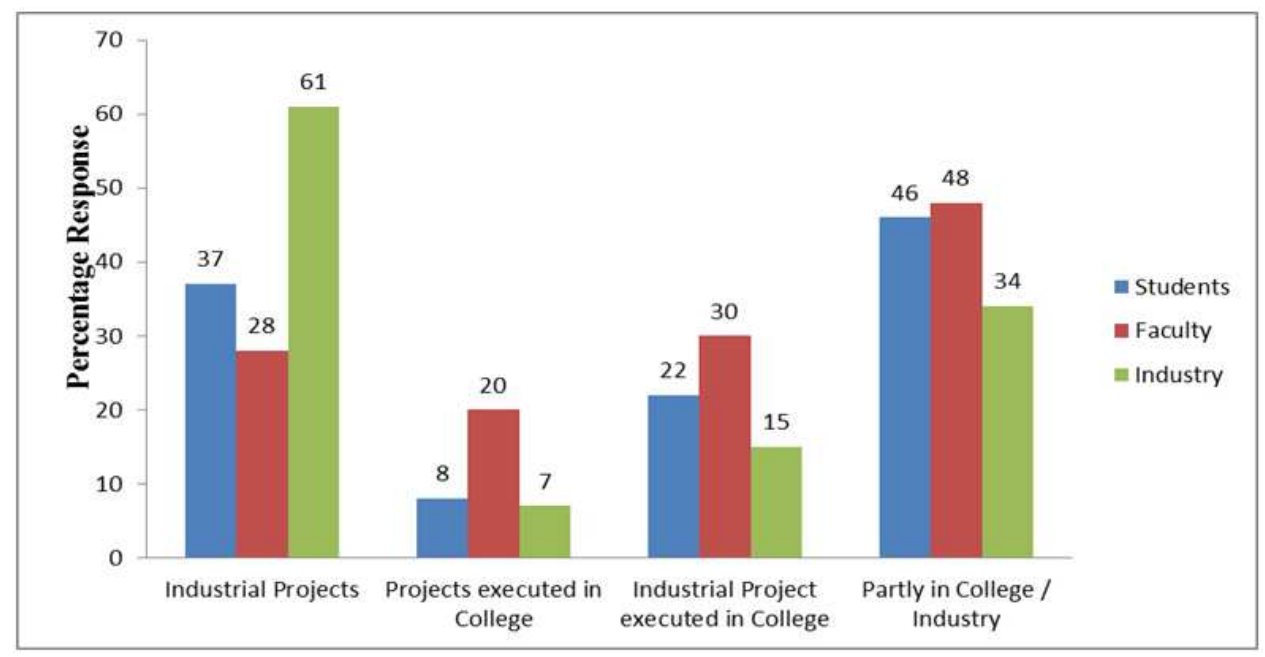

Fig. 2: Percentage of responses from students, faculty and industry professionals for each category of projects

\section{DISCUSSION}

A total of 813 respondents were contacted in the survey carried from June 2015 to April 2016. The majority of the respondents were spread across India and some were from across the globe.

Most of the respondents (344) amounting to $45 \%$ of the surveyed population have indicated that students pursuing post-graduate courses in Pharmaceutical Sciences and Technology, should take up industrial projects. Considering the availability of facilities in the industry in terms of high-end machines, sophisticated equipment, and availability of skilled manpower for supervision and looking into future career prospects, students can work as an intern in the industry for carrying out their research projects during the second year. Thus exposing the students to the cutting edge technology and best practices being used by the industry in drug manufacturing and research. The capacity of the industry to absorb these interns for almost a year across the country and to train them will remain a matter of concern, especially for students coming from academic institutions located in areas with no or little presence of pharmaceutical industries.

On the basis of the personal interviews with select senior industry professionals, it is observed that in some cases these interns are treated as a liability and used only to meet the human resource policy for the company. In such a situation, the students are left with no substantial work and guidance, thus affecting the quality of work they produce during such time. Moreover, to implement the scheme of industrial projects for post-graduate students of pharmaceutical sciences in its true spirits, active intervention from the Government and various regulatory bodies is required. Heavy coordination and follow-up at the University/Institute level would be required. Some academicians are of the view that this may disturb the entire course structure and they will lose control on the monitoring process of the research work or projects being carried out by the students.

$42 \%$ of the respondents stated that the research projects should be carried out partly in academic institutions and partly in the pharmaceutical industry (in collaboration). As stated above, the students carrying their research work fully in the industry, are many times left on their own as industry supervisors are not able to spare time to guide them because of tremendous work pressure and stringent deadlines in completing their routine work. Thus if the research projects are executed with the active participation of the industry in terms of providing their state-of-the-art infrastructure along with the inputs from industry professionals and under the active guidance of faculty supervisors, the students would be in a better position to execute their research projects.
Since these research projects involve the active participation of industry professionals and academicians, the students would be in a better position to grasp the fundamentals of research, develop research aptitude and learn basic skills which can be applied in various domains of industry, thus preparing trained and readily employable professionals. Such mechanisms are being followed in some of the elite academic institutions as they have a very strong industry interface. However, it still remains a challenge for most of the new and specifically private unaided institutions. Sincere efforts are thus required from educational institutions as well as various regulatory bodies to make this happen.

$21 \%$ of respondents opined that students should take up industrial projects and execute them in academic institutions. At times, due to certain limitations like lack of time for conducting the research or non-availability of skilled persons in that particular area of the project or due to financial unavailability, certain projects are outsourced by the industry to academic institutions. These projects normally being a small module of a bigger project needs to be executed using certain set protocols as specified in the industrial manual, thus leaving a limited scope for the students to learn. By carrying out such projects, the students get an hands-on experience of the work being done in the industry and is a potential source of revenue for the institutions and the students as well. But, the very objective of the concept of research projects to be undertaken by postgraduate students stands debatable in this case.

$10 \%$ of respondents are of the view that the research projects at post graduate level should be carried out purely in academic institutions. They are of the view that students should execute their research projects under the supervision of faculty supervisors. Under their guidance, students can develop the skills to conceive and execute a project, develop research aptitude and learn basic skills which can then be applied in any domain of the industry.

The percentage responses of all category of respondents grouped by the mode of execution of research projects is shown in fig. 2 . It is observed that $61 \%$ of respondents working in pharmaceutical industry are of the opinion that students should execute industrial projects. It is pertinent to note here that the ability of the industry to absorb students at this level and devote time to train and guide them is debatable. $48 \%$ of faculty and $46 \%$ of post graduate and $\mathrm{PhD}$ scholars stated that the research projects should be conducted partly in an academic institution and partly in the industry. It is thus clear that the average of percentage responses of respondents who are in favour of students executing a project partly in college and partly in the industry is the highest. This will enable the students to grasp fundamental and applied aspects in the research with its 
appropriate application in the industry and would increase the employability quotient of the students.

Active intervention of the Government and various regulatory bodies would also be required to make this happen. Regulations governing these changes in the mode of execution of projects at the post-graduate level will have to be made and implemented across the country.

\section{CONCLUSION}

A pharmacist is one of the most important stakeholders in the healthcare industry. With appropriate training being imparted in academic institutions coupled with a sound exposure to the best practices followed in the industry, trained and readily employable pharmacists can be produced, who could prove an asset to the organisation they work for and thus contribute to the benefit of society at large. This can be achieved if the research and projects at post graduate level are carried out in academic institutions in collaboration with pharmaceutical industry.

The results of the current study indicate that the research projects at post graduate level in pharmacy if executed partly in the pharmaceutical industry and partly in an academic institution (in collaboration), can produce pharmacists who are readily employable. Students can take up any problem given by the industry and can work with active inputs from the industry under the guidance of the faculty. This scheme, if implemented would thus act as a game changer and will help the Indian pharmaceutical industry get trained professionals and would also help the academic develop a strong industry interface.

\section{CONFLICT OF INTERESTS}

Authors have none to declare

\section{REFERENCES}

1. Ayushi S, Anupam S, Sudhir G. Pharmacy education in India and its neighbouring countries. Int Curr Pharm J 2012;1:294-301.

2. Gazi Mahabubul A, Abul Quasem A. Role of pharmacy education in the national development of bangladesh: a scope for public and private sectors. Indian J Pharm Educ Res 2014;48:11-21.

3. Tharappel LJP, Kaur G, Buttar HS. Pharmaceutical education in India: past, present and future. J Pharm Sci Res 2014;6:278-81.

4. Ansari MT, Rahman SA, Badgujar VB, Sami F, Abdullah MS. Problem-based learning (PBL): a novel and effective tool of teaching and learning. Indian J Pharm Educ Res 2015; 49:259-65.

5. Bhupendra S, Katare 0. Need of quality education for changing pharma world. Indian J Pharm Edu Res 2009;43:203-18.

6. Tipnis HP. Boost to the Universities, But they Must Pull up their Socks. Indian J Pharm Educ Res; 2006. p. 40.

7. Tsingos C, Bosnic-Anticevich S, Lonie JM, Smith L. A model for assessing reflective practices in pharmacy education. Am J Pharm Educ 2015;79:1-10.

8. Vijayanarayana K, Sonal Sekhar M. Bridging pharmaceutical education. Curr Pharm Teaching Learning 2014;6:754-47.

9. Bhuyan B. Pharmacy Education in India: current standard, admission criteria and regulation. Int J Pharm Biol Sci 2013;4:860-6.

10. Breimer DD. Future training needs in the pharmaceutical sciences: academia-Industry. Eur J Pharm Sci 2001;12:347-52.

11. Neelam M. TQM of pharmacy teachers needs and challenges. Indian J Pharm Educ Res 2006;40:132-34.

12. Praneta D. An overview about pharmacy education in India. Indian J Res Pharm Biotechnol 2013;1:329-32.

13. Sanchez AM. Pharmacy education in Cuba. Pharm World Sci 2010;32:696-700.

14. Siva Prasada RMV, Peter K, Ubaidulla U, Marja A. Research public health and patient care aspects in Indian pharmacy curriculum: a comparison between D-Pharm, BPharm, and PharmD programs. Curr Pharm Teaching Learning 2015;7:84-93.

15. Garry L, Lezley Anne H, Sharon H, Carmel H. Developing entrepreneurial skills in pharmacy students. Am J Pharm Educ 2015;79:1-9.

16. Daniel RK, Diane BG, Nathan JH, Joshua JS. The role and responsibilities of pharmacy student government associations in pharmacy programs. Am J Pharm Educ 2015;79:1-4.

17. Ifeachor AP, Ramsey DC, Kania DS. Research survey of pharmacy schools to determine methods of preparation and promotion of postgraduate residency training. Curr Pharmacy Teaching Learning 2016;8:24-30.

18. Mehta N, Asnani A, Pathak A, Rabra V. Need of up gradation of diploma in the pharmacy curriculum. Indian J Pharm Edu Res 2005;39:82-3.

\section{How to cite this article}

- Gouri Palsokar, Madhukar Tajne. Postgraduate research in pharmaceutical sciences in India: a survey of select pharmacy professionals. Int J Curr Pharm Res 2017;9(4):161-164. 